\title{
Migración, Estado y seguridad. Tensiones no resueltas y paradojas persistentes
}

\author{
Luis Eduardo Thayer \\ Universidad Central de Chile \\ Email: luis.thayer@ucentral.cl
}

"Al llegar a determinada fase de desarrollo las fuerzas productivas materiales de una sociedad chocan con las relaciones de producción existentes"

Karl Marx.

\begin{abstract}
Resumen $^{1}$ : A partir de información descriptiva y de la revisión de referencias bibliográficas se analizan las condiciones en que se producen los flujos migratorios contemporáneos, y las consecuencias que enfrentan los migrantes a la luz del fortalecimiento de las políticas de control fronterizo. Se exponen las paradojas y tensiones políticas derivadas de estas políticas de control que impulsan los principales países desarrollados receptores. A partir de ello se realiza un análisis comparado con las políticas fronterizas de los Estados receptores de migrantes durante la primera mitad del siglo XX. El artículo concluye con la tesis de que la reacción contemporánea del Estado frente a las migraciones es una respuesta a la demanda de las sociedades nacionales. La respuesta Estatal contribuiría a su vez a reproducir y alimentar el malestar y el desprecio social por los migrantes, lo que redundaría en una crisis de los derechos humanos como el fundamento que las democracias occidentales se han buscado dar desde la segunda mitad del siglo XX.
\end{abstract}

Palabras clave: migrantes, democracia, derechos humanos, represión

\section{Migration, State and security. Unresolved tensions and persisting paradoxes}

\begin{abstract}
Standing on descriptive information and bibliographyc review the article analizes the conditions in which contemporary migratory flows are produced, and the consequences faced by migrants in the context of the strengthening of border control policies. Political paradoxes and tensions arising from these control policies, are presented as the mainstream of migrant's host developed countries. From there, a comparative analysis of border policies of the host states of migrants during the first half of the twentieth century is performed. The article concludes with the thesis that the contemporary reaction of the State against migration is a response to the demand of national societies. State response in turn contributes to reproduce and feed social unrest and contempt for migrants, which would result in a crisis of human rights as the foundation that western democracies have sought to give since the second half of the twentieth century.
\end{abstract}

Keywords: migrants, democracy, human rights, repression

\section{Migração, Estado e segurança. Tensõesnãoresolvidas e paradoxos persistentes}

Resumo: A partir de informações descritivas e da revisão de referências bibliográficas são analisadas as condições em que se produzem os fluxos migratórios contemporâneos, e as consequências enfrentadas pelos migrantes, tendo em conta o reforço das políticas de controle de fronteiras. Expõem-se os paradoxos e tensões políticas decorrentesdessas políticas de controle que impulsionam os principais países desenvolvidos destinatários. A partir do anterior, realiza-se uma análise comparativa com as políticas de fronteira dos Estados receptores dos migrantes durante a primeirametade do século XX. O artigo conclui com a tese de que a reação contemporânea do Estado perante à migração é uma resposta à demanda das sociedades nacionais. A resposta do Estado contribuiria por sua vez para reproduzire alimentar o mal-estar e o desprezo social pelos migrantes, o que resultarian uma crise dos direitos humanos como o fundamento que as democracias ocidentaistêm procurado dar desde a segunda metade do século XX.

Palavras-chave: migrantes, democracia, direitos humanos, repressão

$$
* * *
$$

\footnotetext{
${ }^{1}$ Este artículo fue realizado en el marco del Proyecto Fondecyt $\mathrm{N}^{\circ} 1140679$ "Estado chileno e inmigrantes latinoamericanos frente a frente. Reconocimiento, respeto y expectativas de incorporación"
} 


\section{La crisis migratoria como crisis de la democracia de los derechos humanos}

El año 2015 estuvo marcado por las tragedias que quedaron plasmadas en algunas imágenes difundidas por los medios de comunicación, en que cientos de migrantes y refugiados morían en el mar, los que tenían la suerte de alcanzar la costa europea con vida eran encarcelados en centros de detención, asistidos por organizaciones humanitarias, o reprimidos brutalmente por la policía.El alto Comisionado de Naciones Unidas para los Refugiados estima que entre 2014 y 2016 más de 10.000 personas han muerto en el mediterráneo intentando cruzar a Europa. Otras 10.000 que se encuentran atrapadas en centro de detención de las islas griegas del Mar Egeoempezaron a ser enviadas a centros en Turquía con condiciones de extrema precariedad, en virtud de un acuerdo de colaboración entre este país y la Unión Europea firmado en marzo de 2016. Estos datos,que ilustran someramente lo que fue bautizado por los medios de comunicación como la "crisis migratoria" no dan cuenta sin embargo de una realidad nueva, más bien, ponen en evidencia la intensificación de una situación que viene ocurriendo desde hace al menos tres décadas en las fronteras europea y estadounidense. De manera que si bien podemos decir que en 2015 no comenzó nada, fue el año en que se superó el límite de lo que hasta entonces era considerado por los Estados europeos como las consecuencias normales del control fronterizo.La llamada "crisis migratoria" no fue otra cosa que un desplazamiento del límite de "lo normal", en dirección de la represión, el control y la consecuente mayor vulneración de los derechos humanos de los migrantes.

Este desplazamiento de la represión fronteriza normal en la democracia europea implica ciertamente una redefinición de las reglas del juego y de las demarcaciones en las que venía inscribiéndose la relación de los Estados europeos y los migrantes extracomunitarios. Lo que por su parte tiene consecuencias en la redefinición de las instituciones y normasque se dan las democracias para regularse, pero también las tiene sobre el significado que adquiere hoy la democracia en Europa. Lo que está en juego con el reordenamiento de la relación entre Estados y migrantes es, para estos últimos el grado de inclusión e igualdaden el acceso a las distintas dimensiones de los derechos, para los Estados receptores en cambio, se pone en juego el modelo institucional de democracia y el grado de democratización que va a definirlos como comunidades políticas (Carens, 2004). En la política migratoria como en ningún otro ámbito de acción del Estado se definen los contornos y el contenido sustantivo de la democracia, y es que los migrantes tensionan la promesa de un régimen basado en el acceso igualitario a los derechos para los habitantes de un territorio. Tal como señalan Weil y Crownley (1994) si la inclusión de los migrantes supone un fortalecimiento de la democracia, su exclusión y la restricción en el acceso a los derechos 'implica en el extremo aquello que hace a la democracia imposible' (op. cit.: 100).

La forma en que los migrantes tensionan la democracia no se agota en las dinámicas de exclusión social efectiva que enfrentanjunto a grupossociales como las minorías sexuales, los pueblos originarios, las mujeres pobres,los jóvenes marginados del sistema educativo, etc. sino que es producida además normativamente por una serie de instrumentos que institucionalizan la exclusión en la propia definición de migrante (Sassen, 2010). Así, a la exclusión por causa de la discriminación social y las restricciones que impone para el acceso igualitario a recursos, se suma la discriminación institucional (Cachón, 2010) formalizada en la normativa que regula el acceso parcial de los migrantes a los derechos y recursos, y que crea así mismo las condiciones para la negación total de derechos (Goldring y Ladolt, 2013). En este sentido la tensión entre migrantes y Estado democrático tiene su base en la institucionalización de la propia categoría de migrante como una serie de restricciones y condiciones que lo distinguen de la categoría de ciudadano. Joseph Carens(2004) ilustra con claridad la tensión que esto supone al señalar que "los principios democráticos se pueden interpretar de diversas maneras, pero, cualquiera que sea su interpretación, entrañan un firme compromiso de tratar a las personas sujetas a la autoridad del Estado ecuánime e igualitariamente" (Carens, 2004: 398) y, continúa: "además, sostengo que la equivalencia de los derechos de los ciudadanos y los derechos de los residentes es un imperativo de justicia" (op. cit.). De manera que todo el conjunto de políticas represivas en que derivó la llamada "crisis migratoria" de 2015 tiene su origen en esta tensión inherente a la relación entre Estado y migrantes.

Sobre esto, sin embargo es necesario hacer una precisión de orden histórico. Si bien la democracia desde su origen se ha construido sobre formas de exclusión social (Arendt, 2003) y de diferenciación entre los ciudadanos y los no ciudadanos, la emergencia en la segunda mitad del siglo XX de los derechos humanos 
como el referente sustantivo de la democracia, marcó un hito que justamente permitió tensionar este principio de exclusión fundante en la construcción institucional de la democracia. La represión en la frontera, por tanto no contradice en principio la noción original de democracia, sino que corroe la forma específica de democracia que los Estados occidentales decidieron darse a partir del término de la segunda guerra mundial. Lo que ha entrado en crisis con la "crisis migratoria" no es por tanto la democracia como tal, que históricamente se ha fundado en la exclusión de distintos grupos: las mujeres, los esclavos, los plebeyos, los pueblos originarios, los pobres y ciertamente los extranjeros, sino la forma contemporánea de la democracia que ha pretendido sentar sus bases sobre los derechos humanos universales. En este trabajo buscamos poner en evidencia algunas de las paradojas y tensiones que permiten comprender de mejor manera la relación de los flujos migratorios contemporáneos y el Estado y las democracias fundamentadas en este principio.

\section{Condiciones para la migración y desprecio}

La intensificación de la represión fronteriza que viene dándose desde inicios del siglo XXI en Europa y EEUU es la radicalización de una política de Estado impulsada de manera continuada y sistemática desde el último cuarto del siglo XX, y específicamente desde la década de 1980 (Sassen, 2010). La crudeza y la visibilidad con que esto se expresó el 2015, es el punto culmine de unapolítica de represión migratoriaque cuenta con una consistencia de poco más de tres décadas, y que con ciertos matices la ha aplicado la gran mayoría de los países desarrollados receptores de migrantes. Las diferencias en la implementación más que expresar divergencias sustantivas en cuanto a la definición de la política de Estado en la frontera, dan cuenta de estrategias distintas para gestionar la demanda estructural de fuerza de trabajo migrante por parte de las sociedades receptoras.Lo que Abad (2003) ha llamado la paradoja de la necesidad del inmigrante indeseado'busca dar cuenta de esta dualidad que enfrentan los gobiernos, y que tiene su expresión política en lo que Castles (2006) identifica como las 'agendas ocultas'de los gobiernos.Estas buscarían por una parte responder, a la política de Estado restrictiva que demandan las sociedades e instituciones locales, y a la vez satisfacer la demanda estructural de migrantes para el mantenimiento de los márgenes de ganancia en sectores muy relevantes de las economías como el turismo, la agricultura, la construcción o los servicios personales, entre otros (Piore, 1979).

La segmentación de los mercados de trabajo en las sociedades industrializadas generada por el desajuste entre las expectativas laborales de los trabajadores nativos en relación a la estabilidad, el ingreso y el estatus (Berger y Piore, 2011) y la oferta laboral disponible explica la existencia de una demanda de trabajadores extranjeros en condiciones de sobre oferta de trabajadores locales. Solo para ilustrar el punto, ya en el año 2002 antes que se desatara la crisis, en España quedaron disponibles 150.000 vacantes no cubiertas en el Instituto Nacional de Empleo del Ministerio del Trabajo, en condiciones en que había un desempleo en poco más de 1,6 millones de trabajadores. ¿En qué sectores quedaron esas vacantes?: servicio doméstico, peonaje en construcción y labores de cosecha agrícola. Vale decir 'empleos para migrantes'. En el caso de las sociedades con niveles más bajos de industrialización como ha mostrado Benencia (2008) para el caso de Argentina, el factor predominante en la segmentación del mercado de trabajo es la existencia de redes sociales migratorias que configuran un segmento con sus propias dinámicas, normas y condiciones. En definitiva es esta demanda adicional de trabajadores extranjeros que se da incluso en condiciones de sobre oferta de trabajadores nacionales, la que los Estados deben regular en función de mantener activos importantes sectores de las economías. Y lo que explica ciertamente que en un marco global de políticas de restricción fronteriza, existan algunas políticas, aparentemente contradictorias con ello, orientadas mantear un contingente suficiente de trabajadores migrantes (Castles, 2006; Hollifield, 2006).

Estas dos orientaciones que conviven en las respuestas públicas frente a la migración, tienen su origen en la contradicción entre la cantidad de migrantes que los ciudadanos de los países receptores están dispuestos a tolerar, y la cantidad de migrantes que demandan sus economías. Más allá de que el 'deseo' o la voluntad de las sociedades esté mediado por percepciones de la ciudadanía, muchas veces distorsionadas sobre la magnitud de los flujos migratorios que realmente reciben las sociedades, es posible establecer la distinción entre los límites y condicionamientos que emergen desde las expectativas que tienela población nativa, y los que surgen desde la demanda económica expresada en las necesidades estructurales del mercado de trabajo y las presiones políticas de los gremios sectoriales (Castles, 2006).La política migratoria se convierte en este sentido en una suerte de animal de dos cabezas, una de las cuales se afirma sobre las expectativas de la 
población y la otra sobre las demandas estructurales del mercado de trabajo y la estructura productiva. La política de represión fronteriza y el endurecimiento de las restricciones para el acceso a derechos está inspirada en la primera; la 'agenda oculta' y la ambigüedad que genera incluso ciertas condiciones para la reproducción de la irregularidad migratoria, descansa en la segunda: 'esto ayuda a explicar las frecuentes agendas ocultas en las políticas migratorias, es decir, las que pretenden perseguir ciertos objetivos, cuando en realidad hacen lo contrario. La aceptación tácita de la migración de mano de obra indocumentada en muchos países a pesar de una vigorosa retórica en favor del control es un ejemplo de ello' (op.cit: 49). Ahora bien, a pesar de la imposición cada vez más intensa de restricciones a la circulación de migrantes, y la pretensión Estatal de regular la frontera como si fuera una válvula de paso, los flujos migratorios crecen a un ritmo superior al que quisieran los ciudadanos sino también los dirigentes políticos de las sociedades receptoras. Mientras los primeros reaccionan a la supuesta crisis del bienestar que amenazan los migrantes, los segundos lo hacen a las presiones de la población y a la supuesta, y en algunos casos efectiva, pérdida parcial del control en la frontera (Sassen, 2001).

La disparidad entre la cantidad de migrantes que las sociedades están dispuestas a admitir y la cantidad de migrantes que quieren o querrán ser admitidos se explica en parte por la intensificación de la degradación social, política, económica y ambiental en las sociedades de origen de los migrantes y refugiados, y por la consecuente consolidación de las desigualdades globales como una consecuencia estructural de la organización del capitalismo avanzado (Sassen, 1988; 2010). Así a pesar de que las economías de las sociedades receptoras para mantener su ritmo de crecimiento y el nivel de vida de su población, requieren llenar parte importante de los puestos de trabajo que producen con trabajadores extranjeros, la situación en las sociedades de procedencia de los migrantes se percibe desde el centro,como una amenaza. Elincremento de las desigualdades entre países expulsores y receptores, y la creciente degradación ambiental, económica y persistente corrupción política de muchos territorios emisores, ha creado la distopía de un mundo sobrepoblado de potenciales migrantes que traen consigo los males y condiciones de vida propios de las tierras de las que se supone huyen. Los migrantes contemporáneos en este sentido no solo son vistos como una amenaza al bienestar de las sociedades receptoras en virtud de su volumen, sino también porque cargan con el estigma de ser portadores de los males que golpean a sus territorios de procedencia: terrorismo, narcotráfico, enfermedades, delincuencia, pobreza, etc.

En el contexto migratorio internacional actual existe un desequilibrio entre la magnitud de la oferta de migrantes y la demanda por parte de las sociedades receptoras. Aun cuando sabemos que siempre es una minoría muy pequeña de los países emisores la que toma la decisión de emigrar y al mismo tiempo en número de inmigrantes en las sociedades ha sido históricamente minoritario respecto de la población nacional (Sassen 2013), estas poblaciones tienden a pensar la llegada de migrantes desde el prisma del descontrol y el exceso. Las desigualdades sociales entre regiones del mundo son tan intensas y visibles para todos, que el temor a que los potenciales migrantes superan la capacidad de absorción de los mercados de trabajo de las sociedades receptoras, está muy presente: 'los candidatos a la emigración, efectivos o potenciales, superan con mucho el número de que los receptores están dispuestos a admitir" (Arango, 2004: 11). Es necesario subrayar ese 'están dispuestos' pues supone que la capacidad de acogida de un país dependerá siempre de su disposición social y política para aceptar a los migrantes y no en una supuesta capacidad económica para producir puestos de trabajo. Cuando en un país no hay empleos que ocupar, los migrantes simplemente no migran a ese país. De manera que el temor a que los migrantes rebasen el umbral de la reproducción económica y hagan estallar el mercado de trabajo no solo contradice toda evidencia histórica,pues nunca ha existido una sociedad que haya entrado en crisis por causa de la migración, sino además es una idea que carece de consistencia lógica pues se asume que los migrantes llegan a una economía estática a la que no contribuyen a producir con su trabajo. Actualmente podemos decir que mientras las economías receptoras, en general, pueden absorber sin problemas a los inmigrantes que llegan a ellas, las sociedades 'piensan distinto'. Los migrantes son hoy necesitados pero no bienvenidos.

En cualquier caso la percepción de que los migrantes potenciales son muchos,no tiene que ver solo con la intensificación de las causas posibles para el crecimiento de los flujos: pobreza, desigualdades y explosión demográfica de los países del tercer mundo, etc., sino también porque las posibilidades materiales y tecnológicas para desplazarse de un país a otro se han multiplicado y lo que implica entre otras cosas una reducción significativa de los costos. A esta reducción de los costos se suma también el hecho de que la circulación de símbolos y la difusión de estilos de vida cada vez más homogéneos, contribuyen a construir 
unas expectativas de vida asociadas al bienestar, el consumo y el desarrollo, que son irrealizables en muchas sociedades. Cuando estas expectativas se generalizan en sociedades donde las limitaciones materiales para realizarlas son muy evidentes, lo más probable es que las personas tiendan a proyectar sus vidas en algún lugar donde puedan realizar estas expectativas. En este punto es necesario matizar la idea del migrante que huye de la miseria, con la de este otro migrante que transita en virtud de un proyecto de desarrollo, normalmente colectivo o familiar. Sabemos en este sentido que los que están más fuera del sistema, los más miserables y excluidos no migran, sino que lo hacen los que están por sobre la media de ingreso y educación de sus países de origen.

El resultado de esta divergencia cada vez mayor entre las expectativas de las sociedades receptoras de migrantes y las condiciones para la emigración, generan un tensión que puede redundar con mucha facilidad en un conflicto entre Estados emisores y receptores de migrantes. El volumen de emigrantes que requieren los países emisores para conseguir un equilibrio demográfica, una reducción significativa de la pobreza y una descompresión del mercado de trabajo es muy superior al existente y, lo que es más importante, muy superior al que están dispuestos a admitir los Estados receptores (Arango, 2004). En efecto, como ya hemos señalado el número de migrantes que los países receptores reciben es muy superior al desearían recibir. De modo que estamos ante una tensión donde por un lado hay una sobre-oferta de emigrantes potenciales y por otro hay una 'sub-demanda' social de migrantes en las sociedades de destino. Ahora, esta tensión descansa sobre una falacia en la percepción de los Estados receptores. Estos asumen que la migración no tiene que ver con ellos, sino con la pura voluntad de sujetos externos y condiciones exógenas a las que ello producen (Sassen, 2013). Los Estados receptores no reconocen de manera explícita la participación que tienen en la producción original del flujo y en sus condiciones de reproducción (op. cit.).

\section{La paradoja del bienestar amenazadoy el principio de la selectividad migratoria}

El temor a que el bienestar alcanzado por las sociedades centrales se vea perjudicado por agentes exógenos como los migrantes, desconoce que ese bienestar es una función de un proceso de acumulación y concentración de la riqueza, basado en la externalización hacia países subdesarrollados de las labores menos productivas: 'los requisitos de la acumulación del capital han llevado al desarrollo de nuevos modos de realización de excedente. Entre estos están la exportación de trabajos industriales al tercer mundo’ (Sassen, 1993: 88).Es justamente esta dinámica estructuradora de la economía global la que crea las condiciones para la emergencia de flujos migratorios entre países ubicados en ambos extremos de la cadena. Dicho de otro modo,las desigualdades entre territorios integrados a la economía global en virtud de su capacidad para generar valor agregado y aquellos que se integran en la economía mundial en virtud de su especialización en ofrecer fuerza de trabajo local para las labores menos productivas del proceso de acumulación, es una función del bienestar de las sociedades receptoras y al mismo tiempo de la precariedad y el estancamiento de las sociedades de procedencia de los migrantes. Es esta dualidad la que crea las condiciones para que se activen los flujos migratorios hacia las sociedades centrales, que son percibidos desde estas como una amenaza a su bienestar. Así, a la paradoja de la necesidad del migrante indeseado se suma esta segunda paradoja de 'las condiciones de producción del bienestar que se experimentan como una amenaza para el bienestar'.

Más allá de esta paradoja y de las condiciones estructurales que incentivan la creación y consolidación de sistemas migratorios, el temor a que una invasión de migrantes degrade las condiciones de vida que han alcanzado las sociedades receptoras no encuentra un fundamento sólido en la historia de las migraciones del último siglo y medio. Muy al contrario,los antecedentes históricos muestran que las grandes invasiones migratorias' que se dirigieron a Estados Unidos, Argentina, Australia y Brasil a principios del siglo XX, o las migraciones masivas de postguerra en las décadas de los 1950 a 1970 hacia Europa,las que fueron ciertamente inducidas por los Estados demandantes, no generaron precisamente una degradación de las condiciones de vida de los residentes nativos, sino todo lo contrario. No es casual que una de las marcas que diferencia a las migraciones contemporáneas de esta otra migración histórica que, por lo demás provenía en un $90 \%$ de Europa (Arango, 2004), es que esta era asociada a la prosperidad, el crecimiento, la reconstrucción o la expansión de la economía, o como ocurrió en el caso de Chile y Argentina la depuración cultural y moral de la población. Vale decir la vinculación de la migración con la degradación del bienestar es un estigma propio de las migraciones en la sociedad global de fines del siglo XX. 
Si bien existen antecedentes de que en el pasado los Estados receptores articularon distinciones entre colectivos de migrantes más deseados que otros (Stefoni, 2011; Durán y Thayer, en prensa), lo cierto es que como señala Sassen (1993) durante el siglo XIX y durante incluso la primera mitad del siglo XX predominó en los principales países receptores una disposición favorable a la llegada de migrantes. Y es que desde el punto de vista del bienestar, se entendía a diferencia de lo que ocurre hoy que la población y los procesos de crecimiento demográfico a partir de las migraciones eran sinónimo de desarrollo y expansión. La acumulación de fuerza de trabajo en una región era entendida como el preámbulo necesario de un salto significativo hacia mejores condiciones de vida.

Aunque esta noción hoy resulta poco verosímil, como subrayan Castles y Miller (1993) es importante considerar que en el escenario migratorio de principios del siglo XX,los principales países receptores fueron sociedades en proceso de expansión económica y de formación de sus identidades nacionales justamente a partir de los procesos migratorios que estaban experimentando. En muchos casos esto permitió que los discursos sobre las identidades nacionales se fundamentaran sobre la base de un ethos de 'país de migrantes', como fue el caso paradigmático de Estados Unidos (Gordon, 1964). Hoy en cambio los países receptores europeos son países cuya imagen está solventada en una autopercepción de homogeneidad cultural e incluso étnica. Es ilustrativo de esto que el Estado alemán recién asumiera a comienzos de los 2000, que era una 'nación de migrantes', algo tarde si consideramos que lo hizo luego de pasar casi medio siglo reclutando y recibiendo fuerza de trabajo extranjera, primero para reconstruir su economía de post-guerra y luego para mantener su crecimiento, y ya con casi 10 millones de residentes extranjeros en su territorio. También es sintomático de esta supuesta homogeneidad nacional como forma de distinción cultural respecto de los migrantes el que en el caso de Estados Unidos, se hubiera transitado de una noción del 'américan way of life' como resultado de un 'melting pot' o 'crisol de culturas' (Gordon, 1964) a la noción en que lo 'americano' está vinculado al prototipo del sujeto protestante, blanco y anglosajón: WASP por sus siglas en inglés.

En el mismo registro, un Estado como el francés construido sobre los principios de un supuesto universalismo republicano (Castles y Davidson, 2001), declaró en 2008 a través de su entonces ministro del interior Nicolás Sarkozy, que aquellos 'migrantes' que fueran sorprendidos realizando desordenes en el contexto de los estallidos de violencia en los suburbios de las grandes ciudades francesas, serían deportados a sus países de origen. Se le escapaba al ministro que los jóvenes que salían en las noches a manifestar su malestar incendiando autos eran en su gran mayoría nietos de migrantes del Magreb llegados a Francia en las décadas del 50 al 70. Vale decir eran jóvenes cuyos padres ya eran franceses cuando nacieron. Una reacción así solo encuentra asidero lógico en una sociedad que no se considera 'de migrantes'.

Esta insistencia en la negación del migrante como parte de la sociedad muestra otra paradoja que se da actualmente en las sociedades receptoras de migrantes, las que siendo sociedades multiculturales tienen temor a la diversidad cultural. Cabe señalar que este temor a la pérdida de la homogeneidad cultural, hoy generalizado, surgió simultáneamente con la instalación de la Eurpoa central como continente receptor de migrantes africanos.

En este punto es necesario hacer una distinción entre el temora la perdida de la homogeneidad cultural, y el hechode que las sociedades receptoras de migrantes se vuelven en virtud de las migraciones más heterogéneas culturalmente. La enorme diversificación de los lugares de origen y destinode los migrantes genera necesariamente una diversificación de la circulación de referentes culturales que transportan los flujos. Esto transforma completamente el escenario cotidiano de las sociedades receptoras, y más específicamente el carácter de las ciudades donde se concentran. En este sentido al multiculturalismose le puede temer, desde el nacionalismo, la xenofobia o el desprecio racista, pero no se lo puede negar como hecho social contemporáneo. Y aquí es donde se da la paradoja de sociedades multiculturales que niegan la diversidad cultural que la constituye. Es paradojal o esquizoide pues implica temer o despreciar a lo que se es o se está llegando a ser.En cualquier caso ambas cosas, el multiculturalismo y el temor al multiculturalismo son fenómenos que han venido a emerger con las nuevas migraciones.

Síntoma de ello es que los Estados receptores hayan comenzado a impulsar políticas migratorias que tienen por objeto 'el problema de la cultura'. Esto marca una diferencia significativa respecto de la reacción Estatal frente a las migraciones de la primera mitad del siglo XX. Entonces, la aproximación a la migración suponía que el migrante se asimilaría de manera espontánea a la sociedad receptora en virtud básicamente del 
contacto creciente con la población nativa y el acceso a las oportunidades sociales y económicas existentes. Así fue por lo demás teorizado por los estudios sociológicos fundantes del campo en la sociología (Park, 1914, 1936; Park y Burgueess, 1969; Gordon, 1964). Había allí una concepción evolucionista y asimilacionista de las relaciones interculturales, pero sobre todo una epistemología liberal frente a la política de incorporación de los migrantes. Al no constituir la integración (asimilación) un problema social serio, no había motivo para que el Estado diseñara una política específica para facilitarla o producirla. Todo estaba en manos de la sociedad y de la capacidad un sistema productivo en expansión para generar y distribuir esas oportunidades. Independientemente de que esta concepción asimilacionista de las relaciones interculturales entre migrantes y nacionales haya fracasado de manera rotunda, principalmente por no haber cumplido la promesa del acceso igualitario a las oportunidades, hoy resulta inverosímil pensar una 'política de la no política' en materia de interculturalidad e incorporación de los migrantes. Con el cambio de siglo se ha transitado en materia de políticas migratorias desde una concepción de la asimilación como un proceso natural, a una idea de la incorporación como responsabilidad de la gestión política del Estado. Este cambio en la concepción de la gestión sin embargo no implicó un cambio en el supuesto fundamental de la mirada asimilacionista: la idea de que las diferencias culturales son incompatibles con la convivencia social, con la integración y con la cohesión. A la expectativa de sujetos culturalmente diferenciados que negocian su existencia con otros, se sigue imponiendo el deseo, utópico de una sociedad homogénea y en el extremo, pura.

A este predominio de una concepción culturalmente homogénea de las sociedades receptoras, se suma el hecho de que en esta cada vez está más presente, la idea de que su realidad contemporánea está marcada por las crisis. Las tesis sobre el fin del Estado de bienestar (Offe, 1973) o el fin del trabajo (Beck, 2000, Rifkin, 2008) marcan de alguna manera un estado de ánimo generalizado que se proyecta a la migración. Independientemente de lo arbitrario e inadecuada de la asociación entre migración y crisis, lo que Michel Wieviorka (1992) identifica para Francia como la utilización del migrante como chivo expiatorio de políticas de contracción y ajuste de la inversión pública, es un hecho que la figura del migrante se ha construido socialmente en relación a esa crisis, llegando incluso a imputársele la causa de la misma. No bastan los innumerables de informes e investigaciones que demuestran de manera contundente que la contribución de los migrantes a la reproducción de los servicios y el bienestar de las sociedades receptoras es un hecho (OIT, 2003), para desmontar una imagen simple que parece estar grabada a fuego a la percepción de la ciudadanía nacional en las sociedades receptoras.

Como sea, a diferencia de lo que ocurrió con la migración principios del siglo XX a EEUU o la migración hacia Europa en las décadas de 1950 a 1970, en que los migrantes llegaban a sociedades en proceso de reconstrucción o expansión económica (Sassen, 2013) los actuales migrantes llegan a sociedades que conciben sobre si mismas un agotamiento de los recursos y bienes públicos. La "aparentemente insaciable demanda de trabajadores extranjeros en los años cincuenta y sesenta" (op. cit: 141), contrasta con el que las sociedades receptoras actuales no solo interpretan el contexto en términos de una crisis del trabajo, sino también, como una crisis del Estado de bienestar y de protección social.

Como parte del mismo proceso la 'competencia internacional entre lugares para la producción' (Sassen, 2007)que contribuye a que muchas industrias manufactureras instaladas en las sociedades avanzadas, trasladen sus plantas desde países del norte hacia países del tercer mundo, es interpretado desde un lente etnocéntrico como la crisis del sistema industrial moderno y no como una transformación del sistema en su conjunto (Bell, 1975;Castells, 2001) incluyendo como parte de ello reorganización territorial de la producción. La propaganda negativa que tiene esta creciente deslocalización industrial (relocalización, en realidad) alimenta así, aún más la percepción de sociedades en crisis, que tienen respecto de si mismos, los países receptores. De manera que si antes estos países tenían una imagen propia asociada a la abundancia, y de los migrantes como un incentivo a su expansión, hoy la tienen asociada a la escasez, y a los migrantes como sus protagonistas (Sassen 1993).

No deja de ser paradojal que esta concepción de las sociedades receptoras europeas y norteamericana, se dé en un momento histórico que no tiene precedentes en cuanto a la magnitud de la riqueza que esas sociedades concentran. Las teorías del desarrollo endógeno (Porter, 1991) y las investigaciones sobre la estructuración territorial de la globalización económica (Castells, 2001; Sassen, 1991) muestran que la producción de valor y las actividades altamente productivas tienden a concentrarse en los territorios, que a la vez, y por lo mismo, se han convertido en los principales polos de atracción de los migrantes. La movilidad 
global de trabajadores y de capital, si bien encuentra respuestas divergentes por parte de los Estados, se orienta hacia los mismos territorios. Según datos de la UNTCAD (2016), un 55\% de la inversión extranjera directa se dirigió a economías desarrolladas, y un 37\% del total solo a Europa y EEUU.Al contrario, apenas un 4,6\% del volumen mundial de inversiones se dirigió a países africanos. La tesis de los economistas neoclásicos en cuanto a que los factores productivos, capital y trabajo, tenderían a distribuirse de manera equilibrada por el planeta, generando una convergencia espontánea y creciente entre territorios intensos en capital y escasos en fuerza de trabajo, y territorios escasos en capital e intensos en fuerza de trabajo, es uno de los mayores fracasos conceptuales de la historia de la economía como disciplina. El supuesto de que los rendimientos de los factores son decrecientes en la medida en que se acumulan y concentran (Abad, 2003), ha sido destruido teórica (Porter, 1991) y empíricamente (Sassen, 1991). Lo cierto es que en la última parte del siglo XX se ha hecho evidente el proceso de concentración de los procesos y labores productoras de valor, más intenso del que se tenga noticia (Castells, 2001).

Esta tendencia a la concentraciónde la especialización y las labores altamente productivas moviliza, junto con la inversión extranjera, una masa enorme de trabajadores profesionales y técnicos provenientes de países subdesarrollados o en vías de desarrollo. Esto es consecuencia de que los trabajadores especializados nacionales simplemente no dan abasto para completar los puestos disponibles que va creando la dinámica de concentración. Ya el año 2000, la OCDE planteaba que 'la escasez de mano de obra es especialmente significativa en las tecnologías de la información y de las comunicaciones; se ha estimado que se necesitan 850.000 técnicos en EEUU y casi 2 millones en Europa (OCDE, 2000: 373). Poco antes el PNUD (1998) había indicado que más de 250.000 trabajadores altamente calificados en Estados Unidos y la Unión Europea provenían nada menos que de África (PNUD, 1998:31), cifra que no sorprende si consideramos que poco menos del 50\% de los trabajadores especializados en tecnologías que se desempeñan en Sillicon Valley, provienen de China, India, Vietnam y Filipinas (Econdatus, 2016).La contracara de este proceso es la dinámica de descapitalización de las sociedades emisoras, para las que la partida de contingentes significativos de sus trabajadores calificados, representa una pérdida significativa y una subutilización de los recursos invertidos en la formación de estos trabajadores. Solo por señalar un dato el Departamento Colombiano de Planeación estimó que en los primeros años del siglo XXI Colombia perdió en torno a los 2.500 millones de dólares anuales por concepto de 'fuga de cerebros'.

Esta descapitalización de los países emisores de la migración calificada es parte de un proceso de concentración del 'capital humano' que va de la mano de una demanda creciente de trabajadores para labores precarias en los mismos territorios. En efecto si la mitad de los trabajadores especializados (extranjeros y norteamericanos) de Sillicon Valley proviene de países asiáticos, el 20\% de los trabajadores extranjeros que residen en ese territorio, (especializados y no especializados) provienen de México. Vale decir la demanda de migrantes en los centros de producción centrales del capitalismo contemporáneo se dirige simultáneamente a trabajadores considerados 'capital humano' y a los que son gestionados como simple 'fuerza de trabajo'. Saskia Sassen anota con claridad la complejidad del proceso: La concentración en localidades de este sector en expansión de servicios especializados y oficinas centrales de las sociedades en las principales ciudades, ha surgido como una importante fuente de trabajos mal remunerados, directa e indirectamente. El efecto directo es mediante la estructura ocupacional de estos sectores. El efecto indirecto es mediante los sectores secundarios y la estructura subyacente a los estilos de vida de los nuevos trabajadores técnicos profesionales de altos ingreso' (Sassen, 1993: 188). La reorganización territorial de la producción genera así una demanda estructural de migrantes para labores altamente productivas, simultáneamente que para aquellas de baja productividad.

En síntesis, la paradoja de sociedades opulentas que se perciben como decadentes, supone que los Estados son represivos solo con una parte de los trabajadores migrantes, aquellos que son llamados a ocupar los estratos más bajos del aparato productivo y la base de la pirámide social. Aquellos que son requeridos para las labores altamente productivas, no solo son bienvenidos sino que reciben importantes incentivos para la llegada y la permanencia. La política estadounidense impulsada por el gobierno de Barack Obama y los beneficios para trabajadores especializados que ha desarrollado la UE desde el año 2008, viene a poner en evidencia que la gestión de las migraciones se inscribe en lo que James Hollifield (2006) bautizó como 'paradoja liberal', según la cual 'mientras que el capital es cada vez más móvil en virtud de políticas de incentivo por parte de los Estados occidentales (liberales), la fuerza de trabajo es cada vez más estática en virtud de políticas restrictivas impulsadas por esos mismos Estados ¿liberales?” (op.cit.). La ambigüedad con 
que los países centrales gestionan los flujos de capital financiero y productivo, frente a la forma en que gestionan los flujos de trabajadores, se expresa también en la forma antagónica con que gestionan a los trabajadores que se consideran 'capital humano' de aquellos que se consideran 'fuerza de trabajo'. Mientras los primeros se mueven en virtud de una virtual supresión de las fronteras para su movilidad, los segundos se mueven a pesar de un fortalecimiento cada vez más intenso de las fronteras. La política represiva en contra de los migrantes por parte de Europa y Estados Unidos es una política esencialmente selectiva que tiene por propósito garantizar una gestión eficiente de los recursos humanos disponibles en un mercado global de trabajadores.

Lo que algunos han llamado la mundialización de las migraciones (Arango, 2005) suele ser definido no en virtud del número agregado de migrantes a nivel mundial, que sigue sin alcanzar el $4 \%$ de la población mundial (OIM, 2015), sino a partir de ampliación de la red de países conectados como emisores o demandantes de migrantes. En efecto,hoy son pocos los países del planeta que permanecen al margen de las dinámicas migratorias, y hoy los migrantes van mucho más que en el pasado de cualquier parte a cualquier otra. Habría que agregar que esta mundialización se produce en el marco de un proceso selectivo en el que una parte los migrantes la mayoritaria, son fuertemente reprimidos en las fronteras, y otra muy reducida y exclusiva es reclutada por los Estados y grandes empresas para la producción global, en virtud de su calificación, este último segmento móvil, circula con la libertad del capital y lo acompaña en lo que Castells (2001) definió como el 'espacio de los flujos'. El programa de retorno voluntario impulsado por el gobierno español el año 2010 para responder al crecimiento del desempleo producto de la crisis económica desatada en 2008, muestra hasta qué punto los Estados demandantes de migrantes están comprometidos con la selectividad de los trabajadores extranjeros. Esta política pública se propuso por objetivo conseguir el retorno de los migrantes a sus países de procedencia a cambio de recibir por adelantado, en tres pagos, los 10.000 euros acumulados en el seguro de desempleo. La aceptación por parte de los migrantes implicaría además de regresar, renunciar al permiso de residencia vigente y comprometerse a no volver a España por un período de tres años. La pretensión de gestionar los flujos migratorios atendiendo a los ciclos económicos es la expresión más clara del principio de la selectividad migratoria, que en el caso de la política de retorno voluntario se quiso reducir a cero.

\section{La previsible intensificación de la tensión entre condiciones y expectativas}

La crisis humanitaria que atraviesa México de sur a norte, en lo que algunos han definido como la frontera vertical, que se expresa en el macabro recorrido de la "bestia de hierro", y las masivas muertes que dejan los botes rebalsados de migrantes, a su paso por las rutas marítimas en el Mediterráneo o el Atlántico, no son otra cosa que consecuencias derivadas de la represión y la violencia directa que ejercen los Estados receptores en contra de los migrantes que intentan atravesar sus fronteras. Las políticas de seguridad y control fronterizo en general logran parcialmente su objetivo de reducir los ingresos de los migrantes, sin embargo consiguen también incrementar las muertes en los trayectos, incentivan las redes de trata y tráfico, incrementan la irregularidad y la vulneración de derechos en los migrantes, aumentan el costo de los traslados y contribuyen a estigmatizar a los migrantes que ya residen en los países de recepción y a los nuevos migrantes, como residentes ilegítimos, lo que redunda en la discriminación y el racismo en las sociedades receptoras. Las políticas de seguridad fronteriza activan así todo un complejo sistema de incentivos a la inseguridad migratoria.

Estas políticas represivas se estructuran en una divergencia entre por un lado condiciones que contribuyen a la emergencia de nuevos flujos y por otro al masivo rechazo social que genera la presencia de migrantes en las sociedades receptoras. La tesis que queremos sostener aquí es que la represión hacia los migrantes es una reacción del Estado a la demanda de las sociedades que gobiernan. Es en esta donde han entrado en crisis los derechos humanos como fundamento de la democracia. El Estado es desde este punto de vista el instrumento a través del cual se ejecuta una voluntad social que predomina, incluso sobre intereses y demandas de la estructura productiva. El desprecio por el migrante, esté inspirado en el temor a perder el bienestar, en el nacionalismo, el racismo o en el más básico temor a la diferencia cultural, es una producción social sostenida en la ignorancia respecto de las consecuencias que tienen los flujos migratorios para las sociedades receptoras, y respecto de las condiciones que producen esos flujos, en especial aquellas vinculadas a la demanda generada en las sociedades receptoras. 
La dualidad entre condiciones de producción de los flujos migratorios y disposición para la aceptación de los migrantes, previsiblemente se va a potenciar en el corto plazo. Y es que ni los Estados de recepción parecen estar orientando sus políticas hacia la recuperación del fundamento de los derechos humanos para sus democracias, ni las condiciones de producción de los flujos parece que fueran a modificarse en los próximos años. La reproducción de esta dualidad entre las condiciones estructurales que incentivan los flujos migratorios y el desprecio social hacia los migrantes que alimenta la represión Estatal, está llevando a la consolidación de la crisis definitiva de los derechos humanos como referente para la convivencia y la construcción de las democracias occidentales.

Las tensiones sociales que se anuncian en las sociedades receptoras y que han llevado a que la política migratoria pase a estar en el centro de las preocupaciones públicas. Y lo ha hecho en el marco de la emergencia primero marginal de partidos abiertamente xenófobos que con el tiempo han ido ganado espacio electoral hasta convertirse en protagonistas del campo político. En países como Francia, Austria, Grecia, Italia, y recientemente en el propio Estado Unidos con la candidatura de Donald Trump, se ha visto como la expresión de un segmento creciente de la sociedad impone al Estado criterios y principios contradictorios con los que este mismo Estado se diera hace medio siglo. La crisis de los derechos humanos como fundamento de la democracia occidental está comenzando a institucionalizarse en el campo político.

Por su parte en las sociedades emisoras los incentivos para que los flujos migratorios se mantengan e incrementen en los próximos años son evidentes. Solo por aludir al principal incentivo económico como son las remesas, estas han cobrado vital importancia a nivel de las familias y localidades receptoras, pero también desde el punto de vista de los equilibrios macroeconómicos que alcanzan los países emisores.En el caso de países como Ecuador y Perú, por poner solo dos ejemplos cercanos, la segunda fuente de ingreso de divisas se debe a las remesas. O sea que en Ecuador son superadas solo por las exportaciones de petróleo y en Perú por la minería. Y superan en Ecuador a los ingresos por la exportación de plátanos y en Perú superan los ingresos por exportación de productos pesqueros. Entérminos absolutos 2010 las remesas llegaron en Ecuador a \$2.800 millones de dólares y en Perú \$2.600 millones de dólares, llegando a representar respectivamente el $7 \%$ y el $3,3 \%$ de PIB de ese año. En países más pequeños como Republica Dominicana yGuatemala las remesas representan en torno al 10\% del PIB (BID, 2010), mientras que en otros como Honduras, El Salvador, Jamaica o Haití no solo son la primera fuente de ingresos desde el exterior sino además representaron para el 2010 respectivamente el $17 \%$, el $21 \%$, el $23 \%$ y el $33 \%$ del PIB. Si bien el impacto que tienen las remesas en el desarrollo de los países de origen es limitado (Abad, 2005) el efecto de corto plazo hace que sean vitales para la reducción de la pobreza local, la activación del consumo e incluso para el acceso de los Estados de origen de los migrantes a la banca internacional (Guarnizo, 2004). Beneficios similares de corto plazo son los que se generan por el efecto de la descompresión del mercado de trabajo que supone la emigración. La reducción de la población económicamente activa, sin embargo además de mantener un desempleo, implica en el mediano plazo una descapitalización de las sociedades que a su vez incentiva nuevos flujos por el efecto de estancamiento. Lo que Massey (Massey et.al. 2002) definieron como el principio de las causas acumulativas, aplica para esta dinámica de descapitalización creciente generada por la emigración, la que incentiva nuevos flujo, que a su vez intensifican la descapitalización y así sucesivamente.

En cuanto a la distribución de las desigualdades entre territorios de origen y destino de los migrantes, los datos disponibles tampoco permiten prever una reducción de las condiciones productoras de los flujos. Al respecto según datos del PNUD en 1967 la diferencia del ingreso promedio entre el 20\% más pobre y el 20\% más rico del planeta era de 1 a 30; en 1990 aumentó de 1 a 59; y en 2000 de 1 a 74 (Abad, 2003). En términos de pobreza absoluta, según datos del Banco Mundial a principios del siglo XXI había 2.800 personas viviendo con menos de 2 dólares diarios, y 1.200 con menos de 1, o sea un $18 \%$ y un $43 \%$ de la población mundial. Por otra parte la ONU estima que el $80 \%$ de la población mundial vive en zonas subdesarrolladas. Proporción que se pronostica va a seguir creciendo debido las tasas de natalidaddivergentes que existen entre países desarrollados y los subdesarrollados: mientras los países desarrollados están en general por debajo de la cifra de reproducción del 2,1, en el conjunto de África esta tasa está entre 4 y 5 hijos por mujer. Adicionalmente en la actualidad el $95 \%$ del crecimiento demográfico mundial se produce en países subdesarrollados (op. cit.). De mantenerse esta situación el crecimiento demográfico mundial previsto por la ONU que para 2050 estima se alcanzará a los 9.000 millones de personas, lo más probable es que potencie aún más las condiciones para la emigración. 
Si asumimos que las desigualdades económicas entre países y regiones del mundo son una de las causas explicativas de los flujos migratorios, podemos afirmar también que el crecimiento de los flujos migratorios es muy inferior al crecimiento de las condiciones sociales que supuestamente los motivan.De manera que la definición de Arango (2004) de la época actual en términos de 'el tiempo de la inmovilidad involuntaria' resulta no solo ilustrativa sino además nos lleva a poner el foco en las consecuencias que tiene esta especie de sedentarismo forzado para las personas que buscan migrar, y no lo logran por completo porque mueren en el intento o lo logran pero al hacerlo lo hacen en tan precarias condiciones que ingresan en un espacio de invisibilidad y negación total de derechos. Los flujos migratorios no se detendrán mientras las condiciones estructurales se mantengan, y con ello la reacción violenta de los Estados va a operar sobre una realidad susceptible de ser intervenida pero irreductible en su dinámica y por tanto la incidencia de esta política de restricción va a seguir teniendo las consecuencias que ha venido teniendo hasta ahora. Si bien va a seguir siendo eficaz a la hora de reducir los flujos, aunque en una medida significativamente menor que la esperada, será muchísimo más eficaz en facilitar la formación de redes de tráfico de personas, en incrementar el riesgo de muerte para los migrantes en su tránsito, en dificultar el acceso de los migrantes que logran penetrar la barrera a permisos de trabajo regulares, incentivando de paso la permanencia en condiciones de irregularidad. Lo que contradice justamente el sentido que tiene toda política restrictiva: que los inmigrantes no entren, o que se vayan. Pero sobre todo cuando el Estado promueve de manera tan decidida esta política de desprecio a los migrantes, no solo responde a una demanda de sus sociedades temerosas, sino además contribuye a esparcir sobre ellas la imagen de sujetos ilegítimos, que racional y calculadamente se decide excluir del sistema de beneficios y seguridades acumulados, porque lo amenazan desde la irracionalidad y la semi-humanidad.

\section{Bibliografía}

Abad, L. V. (2003), “Economía en red y políticas migratorias. ¿Hacia un Mercado Global de Trabajo?”, en Revista Migraciones $\mathrm{n}^{\circ}$ 14. Pontificia Universidad de Comillas, Madrid.

Abad, L. V. (2005), "Impacto de la emigración y las remesas en el desarrollo. Un enfoque desde las 'condiciones iniciales"” en Revista Migraciones $n^{\circ}$ 18, Pontificia Universidad de Comillas, Madrid.

Arango Joaquín (2004-), "Las migraciones internacionales en un mundo globalizado" en Vanguardia Dossier N 22, Barcelona.

Arendt, Hannah. (2003), La condición humana. Paidós, Buenos Aires.

Beck, U. (2000), Un nuevo mundo feliz. La precariedad del trabajo en la era de la globalización. Paidós, Barcelona.

Bell, Daniel (1975), El advenimiento de la sociedad Post-industrial, Alianza, Madrid.

Benencia, Roberto (2008), Migrantes bolivianos en la periferia de ciudades argentinas: procesos y mecanismos tendientes a la conformación de territorios productivos y mercados detrabajo. En Susana Novick, comp. Las migraciones en América Latina. Buenos Aires: CLACSO

Berger, S y Piore, M. (2011), Dualism and discontinuity. Cambridge University Press, Cambridge.

Cachón, L. (2010), La España inmigrante: marco discriminatorio, mercado de trabajo y políticas de integración. Anthropos, Barcelona.

Carens, J. H. (2004), "La integración de los inmigrantes", en Aubarell, G y Zapata, R (eds.), Inmigración y procesos de cambio, Icaria, Barcelona.

Castells, Manuel (2001), La era de la información, vol. 1, Alianza, Madrid.

Castles, S y Miller, M (1993), Theage of migration, Macmillan, Londres. 
Castles, Stephen, y Davidson, Alastair (2001), Citizenship and migration: globalization and the politics of belonging. Routledge, New York.

Castles, Stephen (2006), "Factores que hacen y deshacen las políticas migratorias", en Portes, A. y De Wind, J. Repensando las migraciones. Nuevas perspectivas teóricas y empíricas. pp. 33 - 65. Universidad Autónoma de Zacatecas, Zacatecas.

Goldring, L. y Landlot P. (2013), Producing and negotiating non-citizenship. Precarious legal satus in Canadá. University of Toronto Press, Tornoto.

Gordon M. (1964), Assimilation in americanlife: the role of race, religion and national origins, Oxford University Press, New York.

Guarnizo, L. E. (2004), “Aspectos económicos del vivir transnacional”, en Escribá, A. y Rivas, N (coords.) Migración y desarrollo, CSIC, Córdoba.

Holliefiled, J. (2006), "El emergente Estado Migratorio", en A. Portes y J. De Wind, Repensando las migraciones. Universidad de Zacatecas, Zacatecas, México.

Massey, D., Arango, J., Greame, H., Kouaouci, A., Pellegrino, A. y Taylos, E. (1998), Worlds in motion. Understanding international migration at the end of the millenium. Clarendon Press, Oxford.

OCDE (2000), "El empleo de extranjeros: perspectivas y cuestiones en los países de la OCDE", en Perspectivas del desempleo, OCDE, Paris.

Offe, Claus (1973), Contradicciones del Estado de Bienestar, Alianza, Madrid.

OIT (2004), "La migración y sus consecuencias" en OIT, En busca de un compromiso equitativo para los trabajadores migrantes en la economía globalizada, Ginebra.

Piore, M. (1979), Birds of passage: migrant labour and industrial societies. Cambridge University Press, Cambridge.

Park, R. E. (1914), "Racial assimilation in secondary groups with particular reference to the negro", en The American Journal of Sociology, vol. 19, $\mathrm{n}^{\circ}$ 5. University of Chicago Press, Chicago.

Ídem (1936), Human ecology, en American Journal of Sociology, vol. 41, n 1, pp. 1-15, University of Chicago Press, Chicago.

Park, R. E. y Burgess, E. W. (1969), Introduction to the science of sociology. University of Chicago Press, Chicago.

Piore, M. (1979), Birds of passage: migrant labor and industrial societies. Cambridge University Press, Cambridge.

Porter, M. (1991), La Ventaja Competitiva de las Naciones. Plaza y Janes, Barcelona.

Portes A. y Böröcz, J. (1989), “Contemporary immigration: theoretical perspectivas on its determinants and modes of incorporation”, en International Migration Review, vol23, pp. 606-630, New York.

PNUD (1998), Informe de desarrollo humano , Programa de Naciones Unidas para el Desarrollo.

Sassen, S. (1991), The global city: New York, London, Tokyo. Princeton University Press, Princeton.

Sassen, S. (1993), La movilidad del trabajo y el capital: un estudio sobre la corriente internacional de la inversión y del trabajo. Ministerio del Trabajo y Asuntos Sociales, Madrid.

Sassen, S. (2001), ¿Perdiendo el control?: la soberanía en la era de la globalización, Belleterra, Barcelona.

Sassen, S. (2007), Una sociología de la globalización, Katz Editores, Buenos Aires. 
Sassen, S. (2010), Territorio, autoridad y derechos. De loa ensamblajes medievales a los ensamblajes globales. Katz, Buenos Aires.

Ídem (2013), Inmigrantes y ciudadanos. De las migraciones masivas a la Europa Fortaleza. Siglo XXI, Buenos Aires.

Stefoni, C. (2011), "Ley y política migratoria en Chile. La ambivalencia en la comprensión del migrante", en B. Feldman Bianco et. al. (comp.) La construcción social del sujeto migrante en América Latina. Prácticas, representaciones y categorías, CLACSO-FLACSO- U. Alberto Hurtado, Quito.

Weil, P y Crowley, J. (1994), "Integration in theory and practice: a comparison of France and Britain", en West European Politics, vol. 17, n 2, pp. 110-126. Routledge, Londres

Wieviorka, M. (1992), El Espacio de Racismo. Paidós, Barcelona.

Zapata, R. (2009), Fundamentos de los discursos políticos en torno a la inmigración. Trotta, Madrid.

$$
* * *
$$

Recibido: 12.07 .16

Aceptado: 30.07 .16 